\title{
PENGGUNAAN BEBERAPA JENIS TINTA UNTUK MENGGANTIKAN TINTA TRYPHAN BLUE DALAM PENGAMATAN KOLONISASI MIKORIZA
}

\author{
Hadianur $^{1}$ \\ ${ }^{1}$ Laboratorium Hortikultura, Fakultas Pertanian Universitas Syiah Kuala, Banda Aceh, \\ e-mail: hadianur29@yahoo.com
}

Submisi : 23 Oktober 2019 ; Penerimaan : 17 Juli 2019

\begin{abstract}
ABSTRAK
Pupuk hayati mikoriza merupakan salah satu pupuk yang digunakan untuk mengatasi masalah pada tanah marginal. Mikoriza berpotensi memfasilitasi penyediaan berbagai unsur hara bagi tanaman terutama unsur Phospor $(P)$. Perbaikan pertumbuhan dan kenaikan hasil berbagai tanaman berkaitan dengan peningkatan penyerapan unsur hara $P$ untuk tanaman. Penggunaan mikoriza pada tanaman yang dibudidayakan terlebih dahulu harus diuji apakah akar yang digunakan sebagai inokulannya terkolonisasi mikoriza atau tidak, karena jika akar yang digunakan tidak terkolonisasi mikoriza maka tidak akan terjadi kolonisasi jamur pada akar tanaman target. Konsekuensinya pupuk $P$ yang tersedia di tanah tidak dapat dimanfaatkan oleh tanaman. Trypan Blue $\left(\mathrm{C}_{34} \mathrm{H}_{24} \mathrm{~N}_{6} \mathrm{Na}_{4} \mathrm{O}_{14} \mathrm{~S}_{4}\right)$ merupakan bahan kimia yang biasa digunakan untuk pengamatan kolonisasi mikoriza. Senyawa ini digunakan untuk mempermudah pengamatan terhadap akar yang terkolonisasi mikoriza. Pada dasarnya penggunaan Trypan Blue berbahaya bagi kesehatan manusia sehingga diperlukan satu tehnik yang aman dan tidak berbahaya serta murah untuk proses pewarnaan akar pada pengamatan kolonisasi akar. Penelitian ini bertujuan untuk mengetahui bagaimana tinta yang beredar di pasaran dan mudah didapat dengan harga yang terjangkau untuk menggantikan tinta Tryphan Blue dalam pengamatan kolonisasi mikoriza. Rancangan yang digunakan adalah Rancangan Acak Lengkap (RAL) Non Faktorial dengan 5 ulangan. Jenis tinta yang digunakan terdiri dari Tinta Quink Parker, Epson C664, Aiflo biru dan e-Print. Pengamatan yang diamati adalah perbandingan kolonisasi akar mikoriza. Hasil penelitian menunjukkan bahwa jenis tinta berpengaruh sangat nyata terhadap perbandingan pengamatan kolonisasi akar/kolonisasi mikoriza dan persentase kolonisasi akar. Jenis tinta Quink Parker biru dan Epson C 664 merupakan tinta yang dapat menggantikan tinta Tryphan Blue pada pengamatan kolonisasi mikoriza.
\end{abstract}

Kata Kunci : Kolonisasi; Tinta; Tryphan Blue; Mikoriza.

\section{PENDAHULUAN}

Pupuk Hayati mikoriza merupakan salah satu pupuk yang digunakan untuk mengatasi masalah pada tanah marginal karena mikoriza berpotensi memfasilitasi penyediaan berbagai unsur hara bagi tanaman terutama P. Perbaikan pertumbuhan dan kenaikan hasil berbagai tanaman berkaitan dengan perbaikan nutrisi $\mathrm{P}$ tanaman (Simanungkalit, 2001)

Di samping sebagai fasilitator penyerapan hara, mikoriza juga berpotensi sebagai pengendali hayati (bioprotektor). Pada umumnya tanaman yang mengandung mikoriza mengalami kerusakan lebih sedikit dibandingkan dengan tanaman tidak mengandung mikoriza dan serangan penyakit berkurang atau perkembangan patogen terhambat. Mikoriza Asbuskular dapat menurunkan serangan penyakit terhadap tanaman (Simanungkalit, 1999). Mikoriza juga berperan penting dalam meningkatkan pertumbuhan tanaman agrikultur, holtikultura, dan tanaman hutan (Wubet et al., 2003).

Mikoriza mampu meningkatkan adaptasi tanaman bawang merah terhadap cekaman kekeringan yang 
berkaitan dengan peningkatan pertumbuhan akar, peningkatan serapan air dan hara khususnya fosfor dan nitrogen. Pada kondisi tercekam kekeringan, varietas peka lebih tanggap terhadap mikoriza daripada varietas toleran (Swarsono dan Heru, 2014) dan Damayanti et al., (2014) menyatakan bahwa mikoriza mampu meningkatkan bobot tanaman bawang merah.

Inokulasi mikoriza dapat meningkatkan pertumbuhan kacang merah secara signifikan (Hylton and Ahmad, 1994). Inokulasi mikoriza juga menyebabkan peningkatan fosfor yang signifikan terhadap tanaman kacang merah (Osman et al. 1990; Benadis et al. 2014). Pengaplikasian mikoriza pada tanaman tomat dapat memperpanjang masa berbuah tomat serta inokulasi mikoriza berpotensi penerapan bioteknologi mikoriza dalam hortikultura berkelanjutan (Reguar et al, 2003). Inokulasi mikoriza jenis oryzae dan jamur mikoriza arbuskula dapat meningkatkan pertumbuhan dan kandungan klorofil cabai (Kim et al., 2009)

Mikoriza dapat diaplikasikan dengan beberapa cara yaitu menggunakan tanah yang sudah mengandung mikoriza, menggunakan akar yang sudah mengandung mikoriza. Menggunakan miselia cendawan atau spora mikoriza yang sudah dikemas dalam bentuk kapsul, dengan cara menaburkannya pada lubang tanam sebelum penanaman, dan dengan cara menaburkan tanah yang terkolonisasi mikoriza disekitar akar tanaman (Hardiatmi, 2008).

Penggunaan mikoriza pada tanaman yang dibudidayakan terlebih dahulu harus diuji apakah akar yang digunakan sebagai inokulannya terkolonisasi mikoriza atau tidak karena jika akar yang digunakan tidak terkolonisasi mikoriza maka tidak akan terjadi kolonisasi jamur pada akar tanaman target sehingga pupuk $P$ yang tersedia di tanah tidak dapat dimanfaatkan oleh tanaman.

Berdasarkan masalah diatas maka perlu dilakukan penelitian tentang penggunaan beberapa jenis tinta untuk menggantikan tinta tryptophan blue dalam pengamatan kolonisasi mikoriza.

Penelitian ini bertujuan untuk mengetahui ada tidaknya tinta yang beredar di pasaran dan mudah didapat dengan harga yang terjangkau dapat menggantikan tinta tryphan blue dalam pengamatan kolonisasi mikoriza sehingga hasil penelitian ini diharapkan dapat memberi informasi tentang ada tidaknyanya tinta yang dapat menggantikan peran tryphan blue dalam pengamatan kolonisasi mikoriza dengan harga yang murah dan mudah di dapat.

\section{METODE PENELITIAN}

Pelaksanaan penelitian ini dilakukan di Kebun Percobaan dan Rumah Kaca Fakultas Pertanian dan Laboratorium Hortikultura Universitas Syiah, dari bulan Mei sampai dengan Juli 2018.

\section{Bahan dan Alat}

Bahan yang dipakai pada penelitian ini diantaranya adalah: benih cabai merah, tanah Andisol, polibag pembibitan, pupuk kandang, pupuk NPK mutiara, pot volume $14 \mathrm{~kg}$, $\mathrm{KOH}$, Tinta Quink Parker, tinta printer Epson C664, Tinta printer Aiflo warna biru, tinta printer e Print warna biru, cuka $25 \%$, aquades.

Alat yang dipakai pada penelitian ini diantaranya: timbangan analitik, mikroskop, gunting, pot dan alas pot, peralatan gelas, hot plate.

\section{Rancangan Penelitian}

Penelitian ini menggunakan Rancangan Acak Lengkap (RAL) nonfaktorial $4 \times 1$ dengan 3 ulangan. Adapun faktor yang diteliti adalah jenis 
tinta yang beredar dipasaran dan mudah didapat, yang terdiri dari 4 taraf yaitu:

$\mathrm{T}_{0}=$ Tinta Quink Parker biru

$\mathrm{T}_{1}=$ Tinta Epson C 664

$\mathrm{T}_{2}=$ Tinta Aiflo Biru

$\mathrm{T}_{3}=$ Tinta Data e-Print Biru

\section{Pelaksanaan Penelitian}

Media persemaian dan media tanam menggunakan tanah Andisol yang diperoleh dari daerah Bener Meriah. Media semai terdiri dari komposisi tanah dan pupuk kandang dengan perbandingan $2: 1$. Media persemaian dimasukkan dalam polibag pembibitan dan disusun dalam talam (tray), benih siap untuk dikecambahkan. Sedangkan untuk media tanam penelitian campuran tanah dan pupuk kandang $(2: 1)$ dimasukkan dalam pot isi $14 \mathrm{~kg}$. Tanah dan pupuk kandang yang digunakan diayak dengan ayakan 2 mesh. Benih diaerator dengan aquades selama 60 menit untuk mempercepat perkecambahan. Benih ditanam sedalaman $1 \mathrm{~cm}$ dan ditutup dengan tanah. Mikoriza $5 \mathrm{~g}$ per polybag diberikan pada saat pembibitan.

Pemindahan tanam dari polibag pembibitan ke pot penelitian dilakukan pada saat bibit berumur tiga minggu atau bibit telah mempunyai lima sampai tujuh helai daun. Setiap pot penelitian di tanam satu bibit tanaman. Mikoriza diberikan dengan dosis $10 \mathrm{~g}$ per tanaman atau per pot pada saat tanaman dipindahkan dari polibag pembibitan ke pot penelitian, diberikan disekeliling lubang tanam dan harus mengenai akar bibit tanaman yang digunakan.

Pupuk dasar yang digunakan adalah pupuk anorganik diberikan 1/2 dosis anjuran yaitu Urea $200 \mathrm{~kg} \mathrm{ha}^{-1}$ (2 g per polibag), SP 36 dan KCl $150 \mathrm{~kg}$ $\mathrm{ha}^{-1}$ (1,5 g per polibag). Pupuk Urea diberikan dalam dua tahap, tahap pertama diberikan setengah dosis $(1 \mathrm{~g}$ per polibag) pada saat pindah tanam, sedangkan setengah dosis lagi $(1 \mathrm{~g}$ per polibag) diberikan pada saat tanaman berumur empat minggu. Pupuk $\mathrm{KCl}$ dan SP36 diberikan pada saat tanam. Pemberian pupuk anorganik dilakukan dengan cara sebar di sekitar perakaran tanaman.

Penyiraman dilakukan pada pagi dan sore hari sampai kapasitas lapang, menggunakan wadah dari plastik. Penyulaman dilakukan pada tanaman yang pertumbuhannya tidak normal, mati atau terserang penyakit, dan menggantikannya dengan tanaman lain yang pertumbuhannya seragam. Penyulaman dilakukan paling lambat dua minggu setelah tanam.

Pengajiran untuk tanaman cabai dilakukan saat tanaman berumur tiga minggu dengan menggunakan ajir dari bambu berukuran $100 \mathrm{~cm}$ dan lebar 4 $\mathrm{cm}$ yang ditancapkan pada setiap pot. Tanaman diikat pada ajir dengan menggunakan tali rafia. Pewiwilan dilakukan setelah tanaman berumur 2 minggu pada tunas yang tumbuh di ketiak daun yang berada di bawah cabang utama, dan bunga pertama yang muncul pada cabang utama. Pewiwilan dilakukan agar pertumbuhan vegetatif dapat tumbuh optimal. Pengamatan kolonisasi mikoriza dan persentasi kolonisasi mikoriza dilakukan pada saat tanaman sudah berumur 45 hari atau akhir masa vegetatif. Tanaman dibongkar dengan teliti dan hati-hati agar tidak merusak akar. Kemudian akar dicuci sampai bersih di air mengalir. Akar dipotong-potong sepanjang $10 \mathrm{~cm}$ dan dimasukkan dalam botol sampel.

\section{Pengamatan \\ Persiapan Pengamatan:}

Untuk dapat dilakukan pengamatan maka akar harus diperlakukan terlebih dahulu melalui proses pewarnaan akar (Brundrett el al, 1996) yaitu 
1. Akar dari setiap tanaman dicuci dengan air sampai bersih, kemudian direndam dalam larutan $\mathrm{KOH} 10 \%$ selama 24 jam, sampai akar berwarna putih atau kuning bening.

2. Akar dibilas dengan air bersih agar $\mathrm{KOH}$-nya hilang. Kemudian direndam dalam larutan $\mathrm{H}_{2} \mathrm{O}_{2} 5 \%$ selama dua hari.

3. Akar dibilas kembali dengan air bersih agar $\mathrm{H}_{2} \mathrm{O}_{2}$-nya hilang.

4. Selanjutnya Akar direndam dengan tinta cuka sampai akar berwarna biru.

5. Pengamatan akar dilakukan dengan memotong akar sepanjang $5 \mathrm{~cm}$ yang telah direndam dengan larutan tinta cuka sebanyak 10 potong akar dan ditata di atas preparat serta ditutup dengan cover glass.

\section{Perbandingan Kolonisasi Akar (kualitatif) \\ Perbandingan kolonisasi akar dilakukan dengan cara melihat pewarnaan pada akar dan membandingkan dengan pemakaian tinta quink parker yang dinilai dengan kriteria sangat terang $(\mathrm{C} 1)$, terang $(\mathrm{C} 2)$ dan tidak terang (C3).}

\section{Persentase Kolonisasi Akar (\%)}

Persentase akar terkolonisasi ditentukan berdasarkan kriteria Rajapakse dan Miller (1992) yang dimodifikasi sebagai berikut:

$$
\begin{aligned}
& <5 \% \\
& (\text { Kelas 1) }
\end{aligned}=\text { sangat rendah }
$$

\begin{tabular}{|c|c|}
\hline Jenis Tinta & Pengamatan Kolonisasi Akar \\
\hline $\mathrm{T}_{1}=$ Tinta Quink Parker biru & $1,2 \mathrm{a}$ \\
\hline $\mathrm{T}_{2}=$ Tinta Epson C 664 & $1,2 \mathrm{a}$ \\
\hline $\mathrm{T}_{3}=$ Tinta Aiflo Biru & $2,4 b$ \\
\hline $\mathrm{T}_{4}=$ Tinta Data e Print Biru & $3,0 b$ \\
\hline $\mathrm{BNJ}_{0,05}$ & 0,81 \\
\hline $\begin{array}{l}\text { Angka yang diikuti } \\
\text { taraf } 5 \% \text { (uji BNJ } 0,0\end{array}$ & lom yang sama berbeda tidak ny \\
\hline
\end{tabular}

Tabel 1. Rata-rata Perbandingan Kolonisasi Akar terhadap Jenis Tinta

$$
\begin{aligned}
& \text { - } 6-25 \%=\text { rendah (Kelas 2) } \\
& \text { - } 26-50 \%=\text { sedang (Kelas } 3 \text { ) } \\
& \text { - } 51-75 \%=\text { tinggi (Kelas 4) } \\
& \text { - }>75 \%=\text { sangat tinggi } \\
& \text { (Kelas 5). }
\end{aligned}
$$

Kolonisasi akar dapat diketahui dengan adanya hifa, miselia, vesikula, arbuskula, maupun spora.

Persentase akar yang terkolonisasi dihitung dengan rumus:

Persentase kolonisasi akar:

$=\frac{\sum \text { sampel akar terkolonisasi mikoriza }}{\sum \text { sampel yang diamati }} \times 100 \%$

\section{HASIL DAN PEMBAHASAN}

Perbandingan Kolonisasi Akar (Kualitatif)

Hasil analisis ragam menunjukkan bahwa pengamatan perbandingan kolonisasi akar berpengaruh sangat nyata terhadap jenis tinta yang digunakan. Rata-rata perbandingan kolonisasi akar terhadap jenis tinta dapat dilihat pada Tabel 1.

Tabel 1 menunjukkan bahwa jenis tinta yang lebih baik untuk mengamati kolonisasi mikoriza pada tanaman cabai merah dijumpai pada tinta Quink Parker dan Epson C 664, yang berbeda nyata dengan tinta aiflo dan e-print. Tinta aiflo dan e-print berpengaruh tidak nyata terhadap pengamatan kolonisasi akar walaupun secara statistik nampak berbeda. 


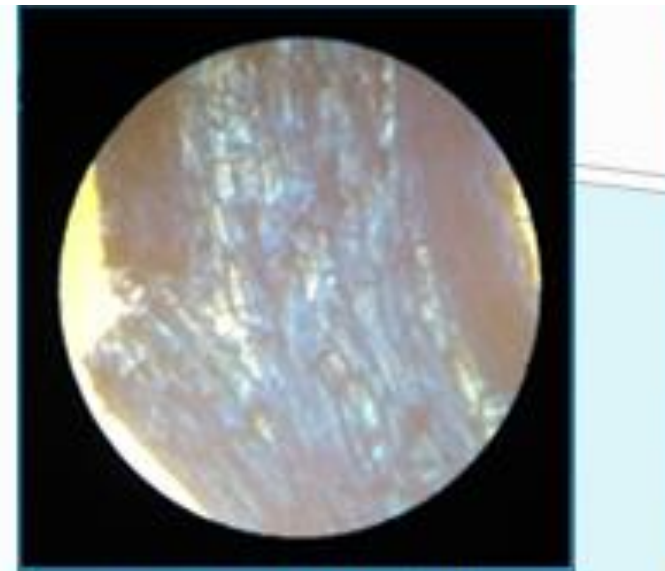

Tinta Quink Parker birt

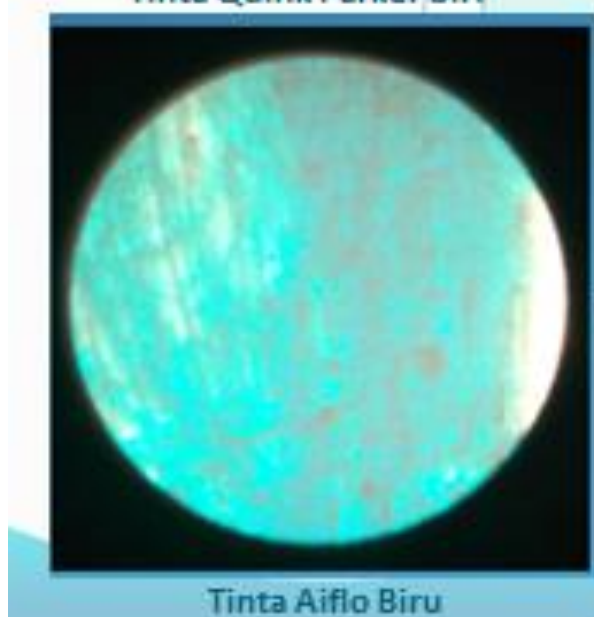

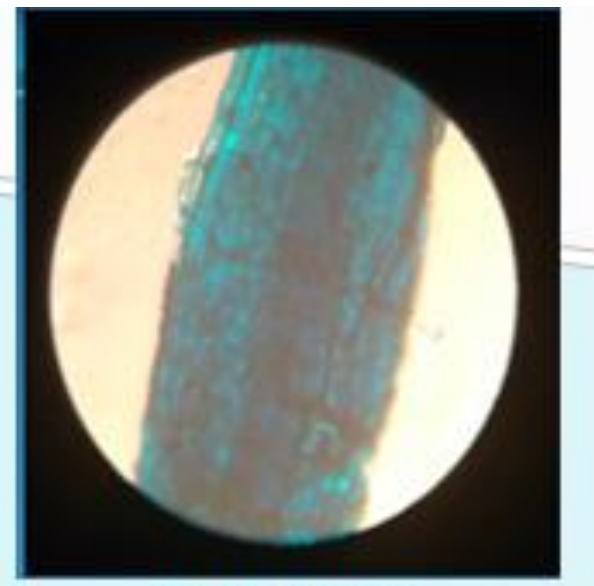

Tinta Epson C664

Gambar 1. Perbandingan penampakan mikoriza pada tinta yang berbeda

Tinta Quink Parker dan Epson C664 dapat mengamati akar yang terkolonisasi mikoriza secara jelas begitu juga dengan tinta Aiflo biru, namun pada sebagian ulangan yang diamati tinta Aiflo biru tidak menunjukkan kolonisasi dengan jelas atau buram. Tinta e-Print biru pada semua ulangan tidak dapat menunjukkan kolonisasi secara jelas hanya samar samar atau buram. Penampakan dari tinta yang digunakan pada pengamatan kolonisasi mikoriza dapat dilhat pada gambar 1 .

Penelitian yang dilakukan oleh Cao et al (2013) menyatakan bahwa tinta tryphan blue dapat digantikan dengan tinta asam asetat biru dari tiga tinta yang digunakan yaitu biru, merah dan hitam. Tinta asam asetat biru dapat menunjukkan warna yang kontras pada pengamatan kolonisasi mikoriza pada tanaman jeruk.

\section{Persentase Kolonisasi mikoriza (\%)}

Hasil analisis ragam menunjukkan bahwa tinta Quink parker biru, Epson C 664 dan Aiflo biru berpengaruh sangat nyata terhadap pengamatan kolonisasi akar mikoriza. 
Tabel 2. Rata-rata Kolonisasi Kolonisasi Mikoriza terhadap Jenis Tinta

\begin{tabular}{lc}
\hline \multicolumn{1}{c}{ Jenis Tinta } & Kolonisasi Kolonisasi (\%) \\
\hline $\mathrm{T}_{0}=$ Tinta Quink Parker biru & $84 \mathrm{~b}$ \\
$\mathrm{~T}_{1}=$ Tinta Epson C 664 & $84 \mathrm{~b}$ \\
$\mathrm{~T}_{2}=$ Tinta Aiflo Biru & $82 \mathrm{~b}$ \\
$\mathrm{~T}_{3}=$ Tinta Data e Print Biru & $12 \mathrm{a}$ \\
$\mathrm{BNJ}_{0,05}$ & 0,81 \\
\hline Keterangan: & Angka yang diikuti oleh huruf yang sama pada kolom yang sama berbeda tidak \\
& nyata pada taraf $5 \%\left(\right.$ uji BNJ $\left._{0,05}\right)$
\end{tabular}

Tabel 2 menunjukkan bahwa kolonisasi mikoriza yang lebih baik dijumpai pada jenis tinta Quink Parker, Epson C 664 T2 dan Aiflo biru yang berbeda sangat nyata dengan tinta ePrint. Kolonisasi mikoriza pada tanaman cabai termasuk kategori sangat tinggi, hal ini dikarenakan akar tanaman cabai dapat mengkolonisasi mikoriza secara baik sehingga spora dapat mensuplai kebutuhan nutrien organisme di dalam tanah yang diperlukan oleh tanaman.

Hasil penelitian menunjukkan bahwa jenis tinta memberikan pengaruh yang sangat nyata terhadap pengamatan kolonisasi akar yang terkolonisasi mikoriza. Penelitian Fitriyah (2012) menunjukkan pemberian inokulan Fungi Mikoriza Arbuskula (FMA) sebanyak 100 $\mathrm{g}$ mendukung perkecambahan spora yang lebih cepat dan kolonisasi akar lebih aktif dalam melakukan kolonisasi akar. Adanya kolonisasi mikoriza pada akar tanaman dapat menyebabkan perubahan morfologi pada tanaman, yaitu mikoriza akan menggantikan peran akar dengan hifa eksternalnya dalam menyerap air dan unsur hara dalam tanah (Prasasti et al., 2013). Sesuai dengan penelitian Junita (2015) yang menyatakan bahwa pemberian mikoriza mampu meningkatkan persentase kolonisasi akar.

Binatang di dalam tanah seperti semut atau colembola dan cacing dapat memakan fungi atau spora dari FMA. Nematoda mungkin juga dapat memparasiti spora namun penelitian tentang hal ini belum banyak dilakukan. Bakteri juga dapat masuk ke dalam spora dan kemudian menghasilkan enzim penghancur dinding sel untuk ke dalam protoplasma dari fungi. Fungi arbuskula mungkin menjadi kurang aktif apabila disitu terdapat juga colembola (springtail). Adanya serangga yang hidup di dalam tanah juga akan mengurangi populasi FMA di dalam tanah (Suhardi, 1989)

\section{Kesimpulan}

1. Perlakuan jenis tinta berpengaruh sangat nyata terhadap perbandingan pengamatan mikoriza dan kolonisasi mikoriza.

2. Jenis tinta Quink Parker biru dan Epson C 664 merupakan tinta yang dapat menggantikan tinta tryptophan blue pada pengamatan kolonisasi mikoriza.

\section{Saran}

Perlu dilakukan penelitian lebih lanjut dengan menggunakan warna yang berbeda dari tinta quink parker dan epson.

\section{DAFTAR PUSTAKA}

Benadis, C., A. Bekki, S. Khoulassa, Boukhatem Z.F, Drevon J.J. 2014. Mycorrhizal colonization decreases respiration of common bean nodulated root in hydroaeroponic culture. 
Symbiosis. Springer Netherlands. Vol. 62. Issue 3:135-142.

Brundett, M., Bougher N, Dell B, Grove T, Malajckzuk N. 1996. Working with Mycorrhizas in Forestry and Agriculture. ACIAR Monograph 32. 374+xp

Cao, M.Q., Q.S. Wu and Y.N. Zou. 2013. An Improved Ink-acetic Acid Technique for Staining Arbuscular Mycorrhizas of Citrus. International Jorunal of Agriculture \& Biologi. 15:386-388

Damayanti, G. Wirian., Purnomo, Bambang., Sariasih., Yenny. 2014. Peran Fungi Mikoriza Vesikular Arbuskula Dalam Menekan Penyakit Bercak Ungu (Altenaria Porri) Pada Bawang Merah. Undergraduated thesis, Universitas Bengkulu.

Fitriyah, E. 2012. Pengaruh mikoriza dan umur benih terhadap derajat kolonisasi, serapan $P$, pertumbuhan dan hasil padi (Oryza sativa L.) dengan Metode SRI (System of Rice Intensification). Majalah IImiah Solusi Unsika 10 (22) : 1-11 Ed. Mar-Mei 2012.

Hardiatmi, S. J. M. 2008. Pemanfaatan Jasad Renik Mikoriza Untuk Memacu Pertumbuhan Tanaman Hutan. Jurnal Inovasi Pertanian, 7: 1-10.

Hylton, K.D.M.D., M.H. Ahmad. 1994. Inoculation response in kidney beans (Phaseolus vulgaris L.) to vesicular-arbuscular mycorrhizal fungi and rhizobia in non-sterilized soil. Biology and Fertility of Soils. Springer Verlag. 18(2):95-98

Junita, E. 2015. Pengaruh Media Tanam dan Fungi Mikoriza Arbuskular terhadap pertumbuhan dan hasil Tanaman Cabai Merah (Capsicum annum L.). Skripsi. Fakultas Pertanian. Universitas Syiah Kuala. Banda Aceh.

Prasasti, O. H., K. I Purwani, \& S. Nurhatika. 2013. Pengaruh mikoriza Glomus fasciculatum terhadap pertumbuhan vegetatif tanaman Kacang Tanah yang terinfeksi patogen Sclerotium rolfsii. J. Sains dan Seni Pomits 2 (2) $: 74-78$

Simanungkalit, R.D.M. 1999. Production of arbuscular mycorrhizae inoculation: forward and challenges. Balai Penelitian Bioteknologi Tanaman Pangan, Bogor. Indonesia

Simanungkalit, R. D. M., 2001. Aplikasi Pupuk Hayati dan Pupuk Kimia Suatu Pendekatan Terpadu, Balai Penelitian Bioteknologi Tanaman Pangan, Bogor. Buletin Agrobio. 4 (2)

Suhardi. 1989. Mikoriza Vesikular Arbuskular. Bioteknologi Universitas Gajah Mada

Swasono dan Heru, F.D. 2006. Peranan mikoriza arbuskula dalam mekanisme adaptasi beberapa varietas bawang merah terhadap cekaman kekeringan di tanah pasir pantai. IPB Repository. Bogor

Wubet,T., I. Kottke, D. Teketay, and F. Oberwinkler. 2003. Mycorrhizal Status Of Indigenous Trees In Dry Afromontane Forest Of Ethiopia. Ethiopian Agricultural Research. Forest Ecology And Management 179: $387-399$ 